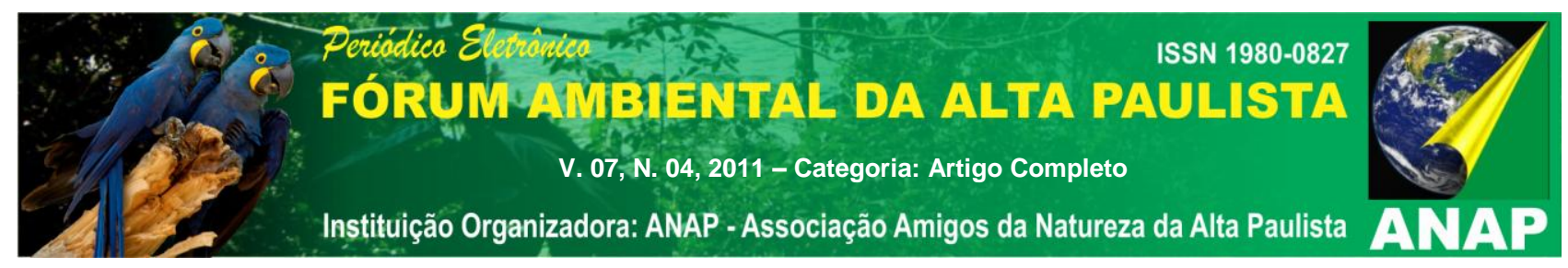

\title{
O OUTRO LADO DA URBANIZAÇÃO: VIDAS REMOVIDAS
}

\author{
Nilzete Ferreira ${ }^{1}$
}

\section{Antonio Carlos de Miranda}

\section{INTRODUÇÃO}

No ambiente urbano a cidade passa a ser local de acúmulo e troca desencadeado pela agricultura, além de uma nova forma de abrigo e controle social, como conseqüência, o crescimento da riqueza institui a divisão de classes, que ocupam de forma diferenciada o espaço da cidade.

Mumford (1965, p.152) descreve de forma clara e atual o desenvolvimento da aldeia, cidadela até a caracterização da cidade reforçando o materialismo histórico:

... a cidade desempenha uma função igualmente importante,...: a função de materialização... ... quando percorremos a cidade, pois os prédios falam e agem, não menos que as pessoas que neles habitam; e, graças às estruturas físicas da cidade, acontecimentos passados, decisões tomadas há muito tempo, valores formulados e alcançados, permanecem vivos e exercem uma influência.

O autor acrescenta a alternação entre a materialização e a eterização em que o significado simbólico assume formas materiais, citando Rousseau: "casas fazem uma cidade, mas cidadãos fazem uma cividade" (apud, 1965, p.127). Essa dicotomia de subjetividade e matéria despontava no pensamento e na prática do ser humano, afirmando que o "planejamento da cidade é, dessa maneira, o ponto culminante de um adequado processo de materialização." (MUMFORD, 1965, p.153)

\footnotetext{
${ }^{1}$ Professora Msc. do Centro Universitário Augusto Motta - RJ - nzferreira@yahoo.com.br

${ }^{2}$ Professor Dr. do Programa de Pós Graduação Stricto Sensu - UNIPLI - RJ - mirantam@ig.com.br
} 


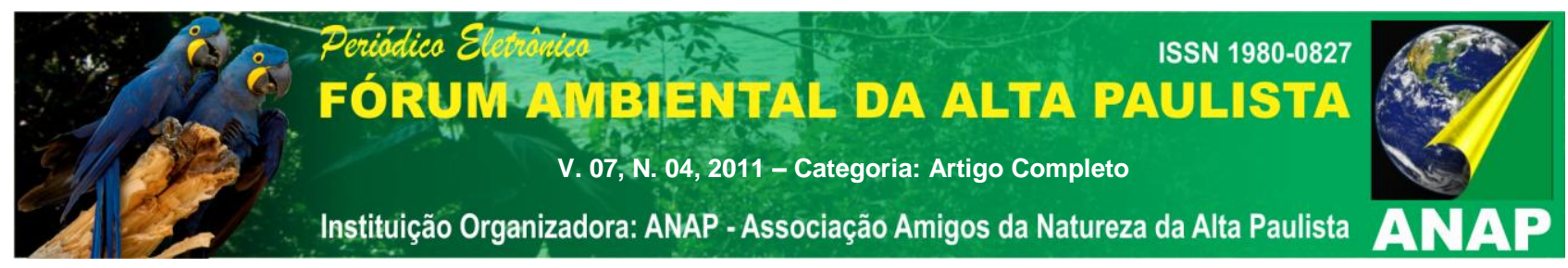

Da aldeia como uma fortificação para sua própria defesa, avançou as muralhas, ganhando mais espaço com o objetivo principal de atender as necessidades humanas. A cidade como escreve Mumford (1965, p.708),

Deve a sua existência, e mais ainda o seu engrandecimento, a tentativas concentradas de controlar outros homens e dominar, com força coletiva, a totalidade do ambiente. Assim, a cidade tornou-se um serviço público de captura do poder, projetado por agentes reais, que reuniam as energias dispersas de pequenas comunidades num gigantesco reservatório, regulavam coletivamente sua acumulação e fluxo e dirigiam-nos para novos canais ora favorecendo as unidades menores pela benéfica remodelação da paisagem, mas com o tempo lançando as suas energias para fora, em destruidores ataques a outra cidade. Libertação e escravidão, liberdade e compulsão, têm-se mostrados presentes desde o princípio na cultura urbana.

Carlos (2000, p.24) vai ao encontro das idéias já expostas por Mumford, salientando ainda que,

a paisagem é humana, tem a dimensão da história e do socialmente reproduzido pela vida do homem. É expressão do trabalho social materializado, mas também é expressão de um modo de vida. A desigualdade que pode ser percebida "no olharse a paisagem" é conseqüência dos contrastes decorrentes do processo de produção do espaço urbano. As relações criam as formas e as funções que devem ser cumpridas.

Na década de 1960 a renovação urbana voltada para o aspecto visual, embelezador, marca uma estruturação urbana que se acelera com a expansão demográfica e a popularização do automóvel, este a exigir mais espaço, impulsiona a construção dos grandiosos viadutos, rodovias, parque de estacionamento, valorizando a core área e "empurrando" uma camada da população para áreas periféricas, desprovidas de saneamento, lazer, transporte. Dilapidando as condições de vida dos trabalhadores, por estarem muitas horas afastadas do seu local de trabalho.

Nesta década, Abreu (2008) aponta à urbanização no Rio de Janeiro como um processo político-econômico, cujos fatores principais na estruturação urbana são: as remoções das favelas em locais mais valorizados da Zona Sul, substituídas por habitações de luxo ou revertidos para "áreas verdes" como reserva imobiliária. Vale lembrar que neste período, o regime militar através de suas ações, fez calar a voz de um povo, legitimando de forma rigorosa através do Al5 (Ato Institucional $n^{\circ} 5$ ). 


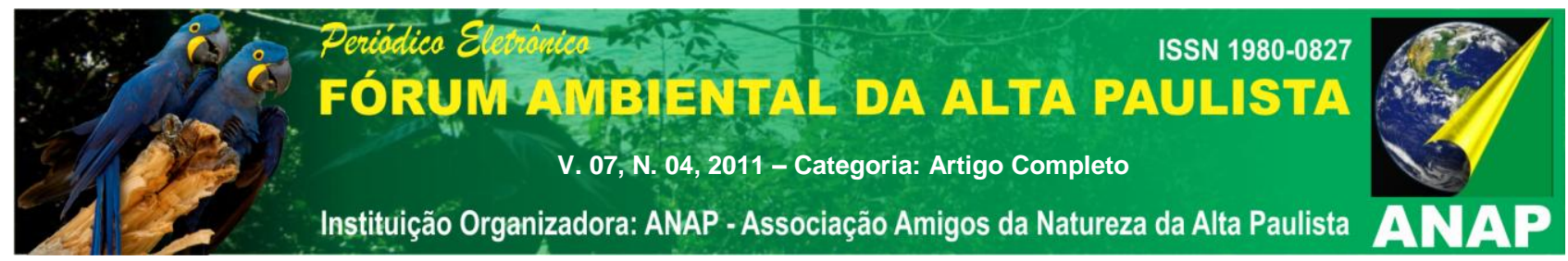

Para tal renovação, a intervenção do Estado na regulamentação, impostos e aquisições públicas passam a ser instrumentos no uso da terra urbana. Contudo, acaba excluindo os pobres das melhores áreas residenciais. Santos (2008a) conceitua urbanização corporativa a rede de agentes vinculados à expansão capitalista que são orientados para investimentos econômicos em detrimento dos sociais, exemplo que podemos observar em Conniff (2006), quando este cita a urbanização da Zona Sul do Rio de Janeiro como um investimento com mais aplicações do que os subúrbios e reconhecido pelos agentes envolvidos por beneficiar a elite e estrangeiros.

O objetivo principal deste trabalho foi analisar a história de vida de moradores removidos, da favela da 'Catacumba" (durante 27 anos fixada junto à Lagoa Rodrigo de Freitas, bairro de alto poder aquisitivo do Rio de Janeiro) para o conjunto habitacional do Quitungo, em 1970, bairro periférico, afastado 20 km (duas horas e meia em transporte público). O conjunto habitacional do Quitungo fica localizado no bairro Brás de Pina, Zona Norte do Rio de Janeiro possui 43 blocos de 40 e 60 apartamentos em cinco andares. Assim como, construir uma reflexão a partir da representação, desses moradores, acerca do espaço urbano e das repercussões em suas vidas provocadas pela remoção, trazendo à tona, em suas falas, o discurso sobre o meio ambiente e a urbanização.

O bairro 'Lagoa', localiza-se no entorno da lagoa Rodrigues de Freitas, Zona Sul do Rio de Janeiro, área extremamente valorizada, e de crescente especulação imobiliária ${ }^{3}$, moradia de classe alta. Neste bairro, a favela 'Praia do Pinto' surge, em 1943, inicialmente, a partir de um "Parque Proletário", como um abrigo temporário. Outras duas favelas ocupavam também a região: 'Ilha das Dragas' e 'Catacumba'. Cabe lembrar que os políticos na "Era Populista", começaram a ver a favela como locus eleitoral, procedimento ainda atual.

A remoção das favelas ao redor da lagoa envolvia os agentes imobiliários, muito mais do que a figura do Estado, em contra partida, Vidigal e Rocinha, outras duas favelas,

\footnotetext{
${ }^{3}$ Valor aproximado do $\mathrm{m}^{2}$. Na Lagoa, R $\$ 12.500,0$; enquanto que no bairro Brás de Pina em torno de R\$3.284,00. Fonte http://www.agenteimovel.com.br/mercado-imobiliario, acesso em 10/8/2011.
} 


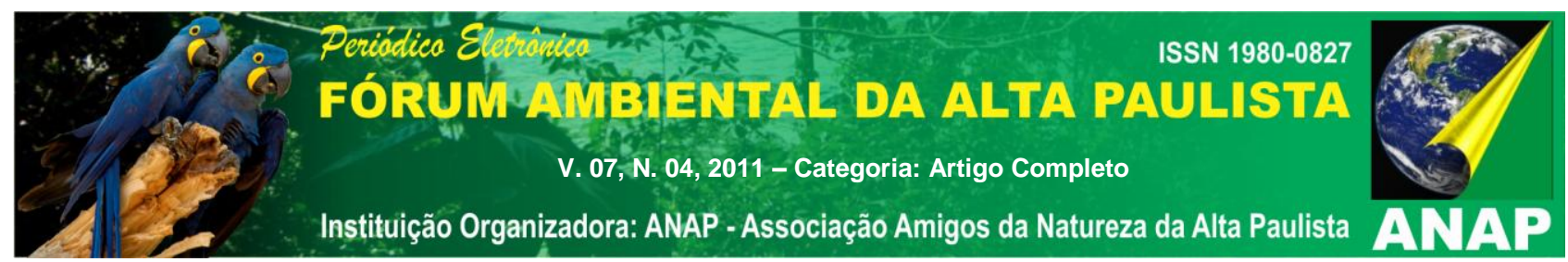

situadas na Zona Sul, continuavam a crescer na mesma época, não sendo alvo de interesse desses agentes, devido as suas localizações nas encostas de morros.

Na década de 1960, as questões sociais eclodiam num período em que o país passava por governo militares. Valladares (1980) lembra que antes do golpe militar, em 1963, o II Congresso de Favelados indicava a urbanização em vez de remoções.

Politicamente, não era adequado expulsar os "invasores" do solo altamente valorizado, mas, sim, 'transferi-los' para um bairro bem afastado, dessa região. Financiados pelo BNH (Banco Nacional da Habitação) e comercializados pela COHAB (Companhia de Habitação), a década de 1960 viu crescer os conjuntos habitacionais, "a massa eleitoral tornou-se uma massa consumidora de habitações" (Valladares, 1980, p.113). Numa faceta do desenvolvimento, ainda nos tempos atuais, a absorção de mão de obra na construção civil, se tornou ícone estatístico, unia assim, a necessidade de comprovar o desenvolvimento no período militar, maquiando uma cidade "limpa" e empregos na área civil, o "milagre" econômico urgia sem uma diretriz urbana e principalmente, social.

\subsection{Materiais e Métodos}

Optou-se pelo estudo de caso, como processo norteador desta pesquisa. Além disso, o resgate de um grupo familiar selecionado, sua representação do espaço, sua memória fazendo parte de uma história coletiva onde espaço e tempo circula indica uma pesquisa qualitativa. Ludke e André assim descrevem a pesquisa qualitativa:

Os dados coletados são predominantemente descritivos. O material nessas pesquisas é rico em descrições de pessoas, situações, acontecimentos; inclui transcrições de entrevistas e de depoimentos, fotografias, desenhos e extratos de vários tipos de documentos. $(2003$, p.1)

Nesta investigação, buscou-se construir a história da comunidade e de sua remoção registrada, em acervos, tais como: Instituto Pereira Passos, Arquivo Nacional e 


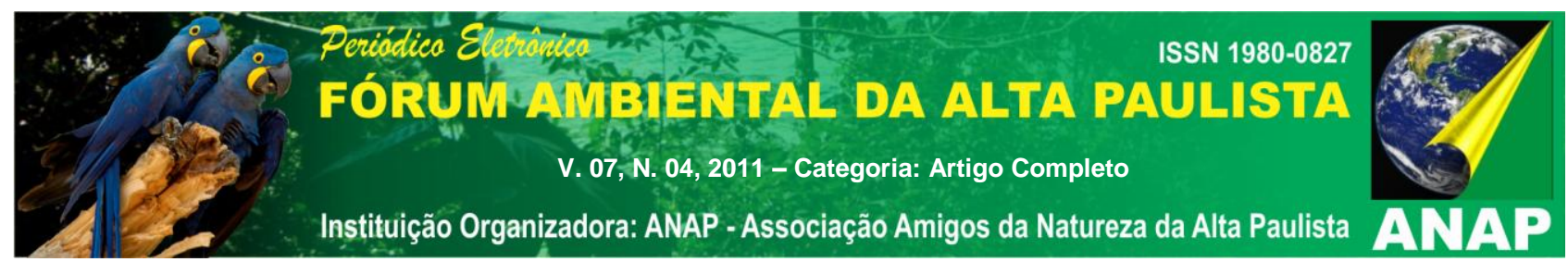

Arquivo da Cidade do Rio de Janeiro. Além de um levantamento bibliográfico, desde a década de 1960, como base para confrontar as idéias de pesquisadores e técnicos com o discurso de moradores do grupo removido da 'Catacumba' para o conjunto habitacional Guaporé-Quitungo.

As entrevistas semi-estruturadas se concentraram nas seguintes moradoras: $\mathrm{E}$. 75 anos e sua filha M., 50 anos, no resgate da memória, construído a partir da interpretação das suas falas, assim como, da análise das fotos do cenário da pesquisa. Optamos em utilizar no texto deste trabalho, pseudônimo sendo eles: E. para Maria e M., Marta.

\section{DESENVOLVIMENTO}

\subsection{A Ocupação}

A casa refletindo a identidade de seu morador, não compreende somente a forma e a estrutura, mas o significado e a memória onde o ser humano é agente ativo na sua história que se reflete em seu ambiente. Maria, aos 75 anos, quartoze filhos sendo sete vivos, conta ser uma das primeiras moradoras da 'Catacumba', filha de imigrantes, diz ter ido para a 'Catacumba' com um ano de idade, lembrando da participação das pessoas na construção:

A minha mãe morava naquele Corte Cantagalo, eu tinha um ano quando ela foi para a Catacumba, um compadre dela é que ajudou eu e minha mãe a fazer o barraco de barro, sabe como né?, de estuque, dormimos no barraco sem janela e sem porta, não tinha barraco nenhum lá, daí depois foi chegando gente pra lá, ficou um mundo de favela, eu me criei ali...

A favela possibilitava a expansão do território, a construção passava a ter uma arquitetura própria ao mesmo tempo uma expressão do grupo. A apropriação do território, a conquista, a posse surge no depoimento da moradora, tanto no início da 'Catacumba' como nas atuais comunidades 'Mangueirinha' e 'Piqueri', favelas que ocuparam áreas, ao redor do Quitungo:

Tinha metade da Mangueirinha não era isso ai não, dali pra cá era tudo mato, depois é que foi enchendo, enchendo e tá isso tudo... muita árvore, muito mato, lá em cima não tinha casa, onde era esse morro...foi fazendo no morro, porque ai falava: tô marcando lugar, as mulheres corriam e para sair do aluguel, marcava lá, 


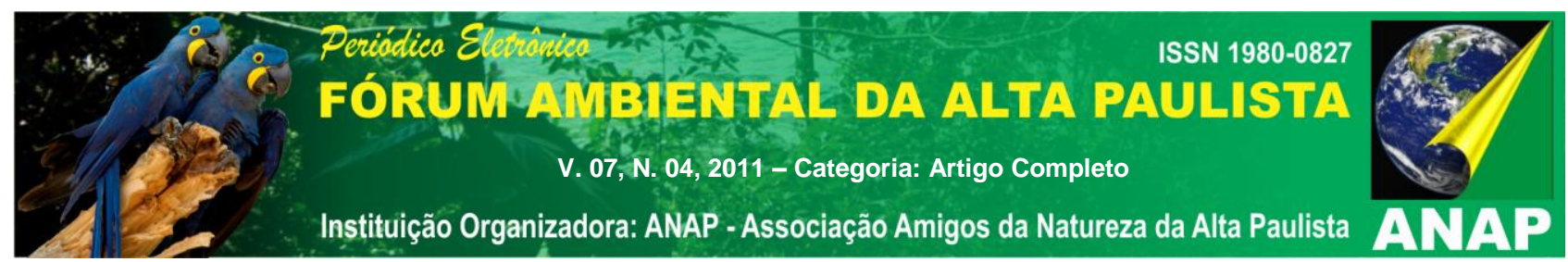

fizeram barraco, casa lá, todo mundo...quando chegou aqui e tinha que pagar, o pessoal ficou agitado da vida

Santos (2007, p.98) ao fazer a leitura dos pobres da cidade, observa que nem mesmo as melhorias na residência lhes dão a condição de propriedade, enfatiza que esta "propriedade da casa ou do terreno é a propriedade de uma mercadoria dentro de uma sociedade mercantil".

Marta 50 anos, dois filhos, filha mais velha de Maria, vive hoje em dia em um cômodo na 'Mangueirinha' (favela que se formou ao lado do conjunto habitacional) com sua filha e neta num espaço dividido por um banheiro, sala que ao mesmo tempo é o quarto, sinalizado por um colchão de solteiro no chão, e uma cozinha, em sua fala, diz ter construído a casa. A laje é usada para estender as roupas que "lava pra fora". Relata como conseguiu a casa atual:

eu ganhei, estava morando de aluguel, ai tem um garoto que viu meu problema e essa casa tava vazia ( ...) morava com minha mãe, morava embaixo, ai fiz um quartinho vendia salgado, sobrevivi, com a minha filha, sou separada (...)lá embaixo morava de aluguel passava fome, tinha vezes que na minha casa tinha arroz e feijão (...)aluguel nos conjuntos é muito caro, hoje nós estamos aqui, tá chovendo aqui, o rapaz vai arrumar um cimento para botar aqui(...)eu luto muito tenho medo da fome, de passar fome.

As condições de habitações, já era um tema abordado pelos políticos no período do Império, segundo Chalhoub (1996, p.32):

Em ofício enviado pela Secretaria de Polícia da Corte ao Ministério dos Negócios do Império, em março de 1860, eram novamente os preços "de tal modo exagerados" dos "alugueres de casa" que explicavam o surgimento e a proliferação dos cortiços.

A relação da especulação imobiliária é vivenciada até hoje pelos agentes sociais, modelando ou, até mesmo, desfigurando o ambiente, traduzindo a luta não somente por um espaço, mas para a construção de uma vida, na expressão de Marta "sobrevivi", sinônimo de escapar, enfrentar, atravessar. Não só a favela, mas espaço vivido torna-se espaço de "resistência e sobrevivência" assinalado por Corrêa (1989), palco de lutas. Santos (2007) observa o ciclo entre a especulação e déficit de residências 


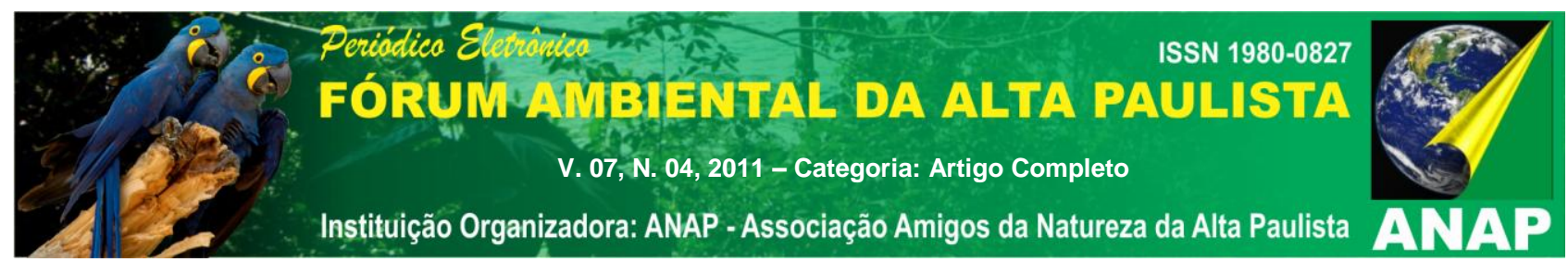

conduzindo a "periferização da população mais pobre" onde a "cidade econômica" se sobrepõe a "cidade social", não incluindo na lógica do mercado o "espaço do cidadão".

\subsection{A Remoção}

As condições precárias de saneamento, energia, entre outras, propiciava a favela um palco de incêndios. A 'Praia do Pinto' vivencia uma demorada remoção onde já sem resistência de luta, um incêndio destrói mil barracos, acelerando a desocupação da área, cujo material restante dos barracos era queimado ou jogado na lagoa. Das 2.300 famílias da "Catacumba', 61\% foram transferidas para o conjunto habitacional GuaporéQuitungo', segundo Valladares (1980), inclui-se ainda moradores da favela 'Praia do Pinto', e das favelas 'Manguinhos', 'Catacumba', 'Maré', entre outras.

A população passa a ser um instrumento de ordenamento espacial bem acentuado na década de 1960 e principalmente no pós-64. O termo de segregação residencial induzida utilizado por Souza (2007) passa a ter um cunho político onde a identidade regional dificulta o estabelecimento de laços de solidariedade de maior consistência político-social, já que para o mesmo conjunto, foram destinados moradores de diversas favelas, perdendo raízes e a identidade de grupo, conforme a fala de Maria: "lugar que a gente tá acostumada, sair é muito ruim, veio gente de outro lugar, misturou , misturou..."

Valladares (1980) aponta em seus estudos que no período de remoção já não se via a resistência da população, o último incêndio na 'Praia do Pinto' culminou a completa remoção da população. Os relatos dos entrevistados corroboram a hipótese de que o incêndio foi planejado para antecipar a remoção.

O interesse pela especulação do local é ilustrado na fala de Maria ao ser perguntada se sabia qual a razão da remoção:

Teve uma época que era a pedra, era a pedra, eu morava bem perto da pedra, a tal pedra que ia rolar, que a pedra ta ainda lá, até hoje lá, foi aquela confusão Eu falava, se vai rolar, eu sou uma que vou morrer primeiro, vocês morrem depois, ai nada. É que subiam uns americanos lá, sempre subiam os americanos, aquelas americanas achava aquilo 


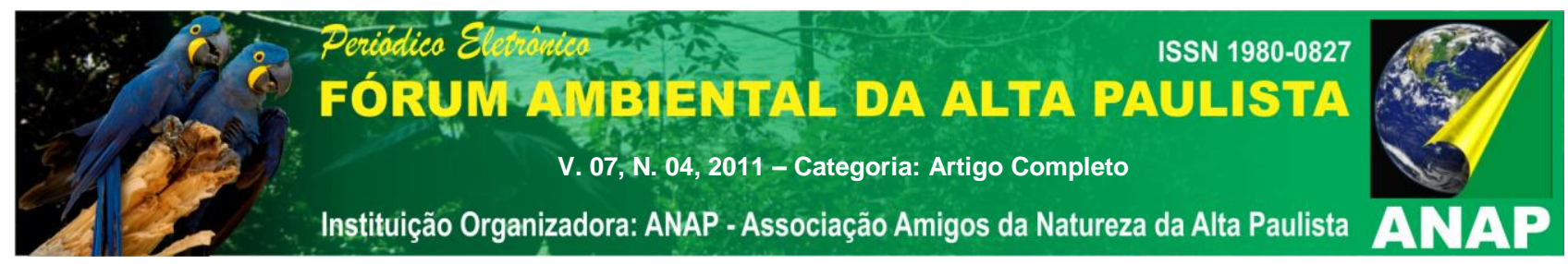

bonito, lá de cima via o Miguel Couto, os cavalos correndo, o jóquei, tinha que ver, o Cristo a gente via frente a frente, ai eles achavam muito lindo.

A especulação imobiliária e as melhorias no espaço público são apontadas por Santos (2008 b, p125) como fatores de expulsão de classes pobres; "todo melhoramento numa área pobre faz dela o teatro de um conflito de interesses com as classes médias em expansão, para não falar das classes altas." No caso das favelas ao redor da lagoa, as áreas foram convertidas para espaço de lazer e construções para as classes médias e altas.

As favelas, ao longo da lagoa Rodrigues de Freitas, possuíam sua limitação regional, ao serem transferidas para o conjunto Guaporé-Quitungo, há a perda de referencial, podemos observar na fala de Maria no início de sua chegada ao conjunto: "Não saia de casa, não sabia andar aqui não, a minha filha mais velha, essa é que ia... no dia que eu fui ali embaixo na COHAB, eu me perdi, ali embaixo, eu me perdi."

Perguntada sobre a lembrança da remoção, Maria explica com detalhes o dia que ficou registrado na sua memória, memória marcada de ressentimentos até na descrição de sua ação e em suas palavras:

ai subiram aquelas moças, aqueles moços, aí chegavam na porta da gente: não, vocês não vão pagar nada, vai pagar só $C R \$ 1,20$ naquela época, não vai pagar mais nada que isso, era o que eles falavam, mas eu não acreditava, eu falava: isso é mentira, duvido, eles não vão tirar agente. Aí quando é um dia, o pai dos meus filhos que trabalhava em dirigir ônibus, acordou cedo, ele falou acorda aí para você vê uma coisa...aí quando acordei e sai do lado de fora da casa e olhei pra baixo, era bombeiro, era polícia, era assistência, eu falei gente o que é isso?

Em seu depoimento, diz, ainda: "eu vim aqui pra esse troço". Utiliza a palavra 'troço', que reforça o seu sentimento de mágoa, mesmo após 38 anos no local. O que nos faz lembrar Santos (2008b, p.328) quando afirma:

Vir para a cidade grande é, certamente, deixar atrás uma cultura herdada para se encontrar com uma outra. Quando o homem se defronta com um espaço que não ajudou a criar, cuja história desconhece, cuja memória lhe é estranha, esse lugar é a sede de uma vigorosa alienação

Confirmando os estudos de Valladares (1980), frequentemente, por não possuir renda capaz de assumir a despesa da nova "mercadoria", apresenta-se uma nova 


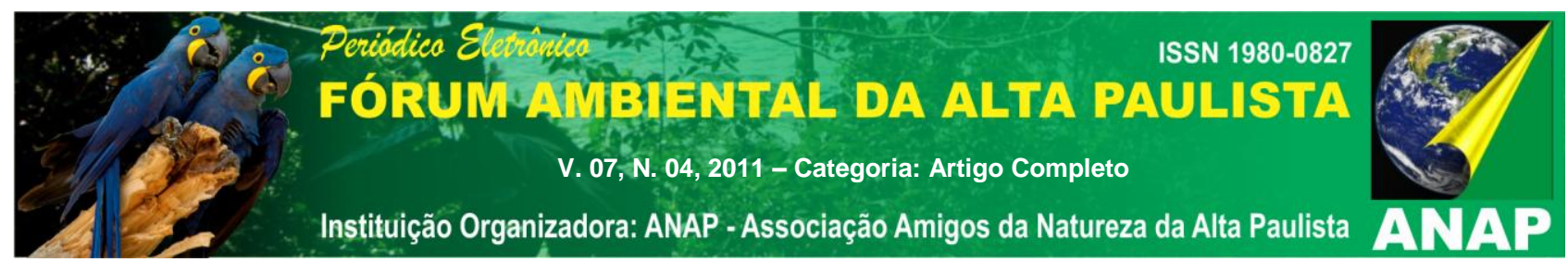

'remoção' para aquele que não consegue arcar com o pagamento de prestações. Com diz Maria houve uma grande dificuldade em pagar as 300 prestações; "era uma tristeza, e a gente que não tinha nem o que comer, pagar casa..." , muitos foram morar em favelas, como a 'Mangueirinha', neste ponto, a história se repete.

\subsection{O Espaço Público, o Meio Ambiente e o Lazer}

No início da remoção, Marta conta que havia calçadas e era aberto à circulação entre os conjuntos, os muros e as barracas foram feitos depois, hoje basicamente, as calçadas não são transitáveis em vários blocos. Situação verificada em vários bairros do Rio de Janeiro, sendo ocupada pelo comércio tanto ambulante quanto de estabelecimentos formais.

O trânsito de pessoas pelo conjunto é feito nas ruas, dividindo o espaço com os inúmeros carros, pois as calçadas foram alteradas para acréscimo do comércio informal. A rua representa não só a via pública, mas um território de circulação e liberdade, espaço onde o lazer é explícito e aceito com a participação do grupo social. Silva (2003, p.48) referindo-se ao arrasamento do Morro do Castelo, lembra que:

as elites e as classes médias, desde o início do século, estavam tomando conta dos espaços públicos da cidade, mas isso não era novidade para os moradores pobres do Castelo, que já o haviam transformado num grande cortiço. Muito antes das elites "irem às ruas", as lavadeiras, as prostitutas e os malandros faziam da rua a sua casa.

O espaço público é um espaço social que para Souza (2007, p.99)

é ao mesmo tempo, um produto das relações sociais, e um condicionador dessas mesmas relações. A organização espacial e as formas espaciais refletem o tipo de sociedade que as produziu, mas a organização espacial e as formas espaciais, uma vez produzidas, influenciam os processos sociais subseqüentes.

Em contrapartida, inaugura-se em 1979 o Parque Carlos Lacerda, na Lagoa, exatamente na área onde era a favela da 'Catacumba', com as especificações dentro dos padrões para urbanização de parques e praças, sendo uma das melhores áreas de lazer da Zona Sul do Rio de Janeiro, ao mesmo tempo, ao redor dos conjuntos também havia 


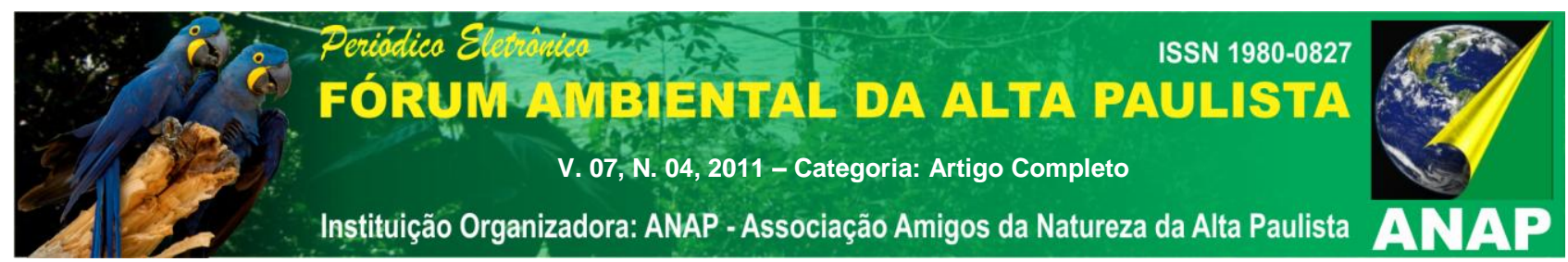

uma extensa área, não sendo destinada à "reserva verde", nem ao lazer, assim facilitando nova ocupação de uma favela.

Andrade (2006, p.110) lembra alguns aspectos físicos "quanto a praças e parques, sem desprezar o papel da gestão desses espaços, os autores falam da importância da existência de elementos como rampas, da disposição do mobiliário urbano e da urbanização." Mumford (2004, p.430) ao rever a história sobre a praça, aponta que estas inicialmente, foram construídas para estacionamento de veículos, transformadas através de quintais residenciais, com a redução e busca de imóvel na conversão do lucro, já no século XVIII;

a transformação da praça residencial foi mais além. No traçado da maioria das praças, destinara-se espaço insuficiente para os quintais; na verdade, esses quintais não demoraram a se transformar em áreas calçadas utilitárias, onde se batiam tapetes e se penduravam roupas para secar. Quando essa falta foi suficientemente sentida, os proprietários das casas da praça transformaram o espaço aberto vazio num jardim ou parque comum.

Outro dado que podemos observar, está na arborização que, de acordo com urbanistas como Farah (2006, p.167), "as árvores podem suscitar forte identidade à paisagem, tornando o ambiente mais acolhedor, facilmente identificável, contribuindo para uma paisagem afetiva." No espaço dos conjuntos, hoje só possuem em torno de $3 \%$ de árvores (dado fornecido pelo representante da Associação de Moradores). O espaço da praça passa a ser um importante espaço para o lazer, o quintal cada vez mais reduzido, hoje temos o "play" e a laje. É na laje, o único espaço aberto, onde Marta estende as roupas e os tapetes como meio de trabalho. Nos conjuntos, são visíveis varais nas janelas, esta situação incorpora a representação social de favelização.

Maria a ser perguntada sobre o lazer comenta sobre muitos "divertimentos", porém não os cita em sua fala: "aqui tem bom divertimento, mas eu quase não saio, tem uma cadeira que eu boto ali e fico sentada, pode vir de tarde que eu tô sentada ali."

Nesta fala identifica-se o vazio das atividades como se tivesse perdido o referencial do espaço. A circulação e opções na Catacumba são relatadas pelas entrevistadas sendo local "perto de tudo, trabalhar, comprar uma coisa, pra ir pra 


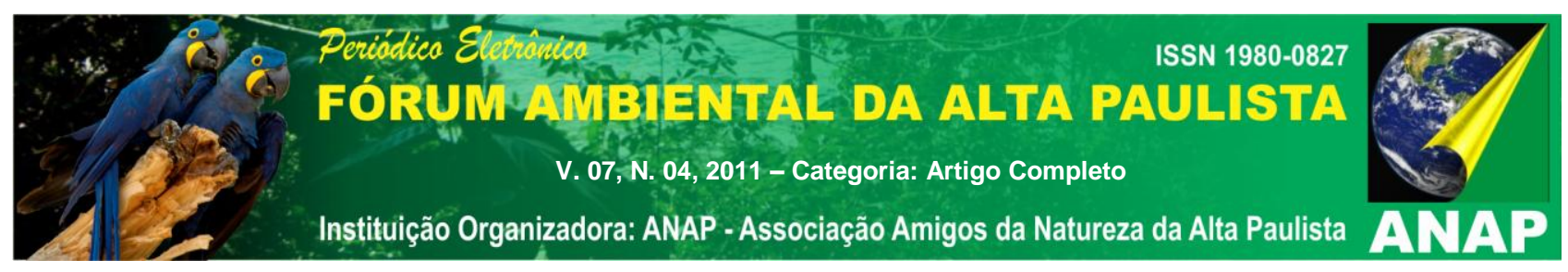

Copacabana, Ipanema". O significado de lazer reflete na forma de dispor de um tempo para entretenimento, ou mesmo descanso, nos conjuntos, os bailes são realizados em espaços abertos onde antes eram os campos de futebol, não respeitando a Lei do silêncio, segundo os moradores, a proximidade com os apartamentos interfere no descanso.

Souza (2007, p.84) inclui à pobreza urbana e à segregação residencial, a degradação ambiental em que observa o lucro até nas conseqüências negativas, envolvendo de forma indireta a população do seu entorno sem a percepção dos impactos a si própria. O autor lembra que "nossa formação territorial é, numa perspectiva histórica, essencialmente degradadora dos lugares e de seus habitantes." (SOUZA, 2005, p.58). Segundo o presidente da Associação de Moradores, o próprio Estado realizou a canalização direta para o rio Quitungo, como "solução" para as favelas 'Mangueirinha' e 'Pequiri', a dialética na figura do Estado,

diante da questão ambiental manifesta uma situação paradoxal: parte de seu aparelho constitui os principais canais institucionais de defesa da qualidade do meio ambiente, outra parte constitui os principais agentes de degradação. (SOUZA, 2005, p.57)

A foto $\mathrm{n}^{\circ} 1$ representa a continuidade do rio Quitungo, observamos a diferença ao longo do rio, que margeia o conjunto habitacional em questão, com esgoto sendo lançado in natura enquanto, contrapondo-se ao seguimento do outro lado da estrada do Quitungo, com propriedades particulares e maior arborização ao longo, podemos observar o rio, como uma natureza "morta", sem vida, sem movimentos.

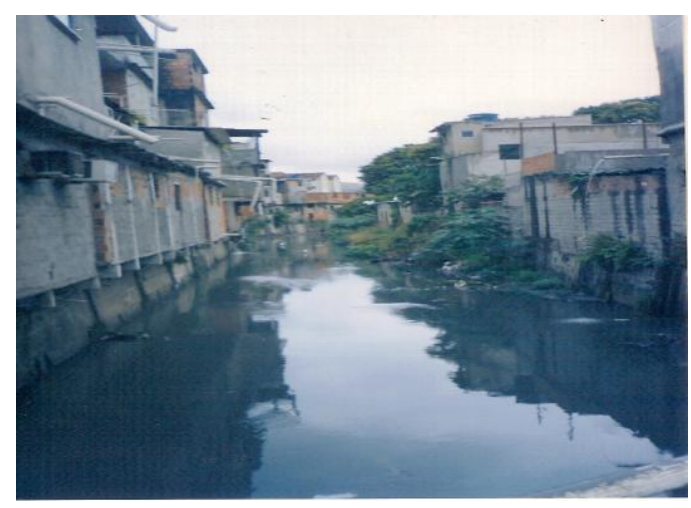




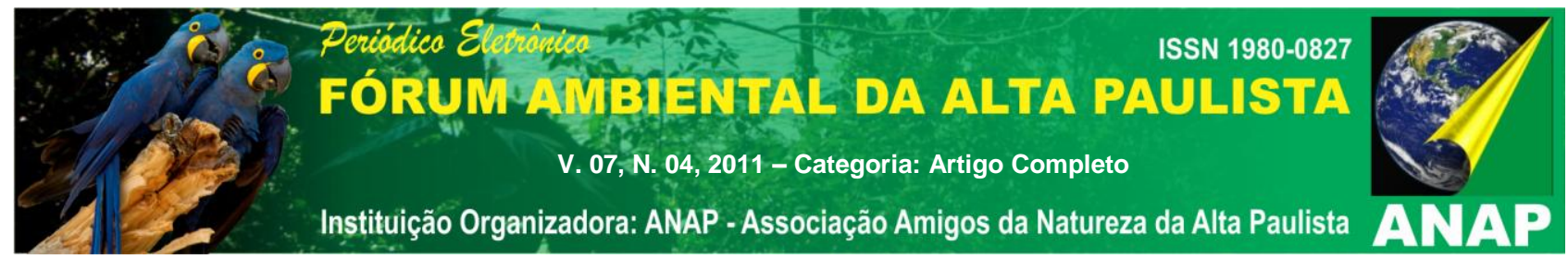

Foto $n^{\circ}$ 1: rio Quitungo paralelo ao conjunto habitacional. Autora: Ferreira, N. (2008)

Costa (2006, p. 152) aponta para a não percepção dos rios pela população que vive e trabalha nas suas margens onde o reduz a canal de drenagem e saneamento, não sendo incluídos pelos profissionais do urbanismo em seus projetos, salientando a importância das bacias hidrográficas. Miranda (2006, p.48) indica duas causas para a degradação das águas urbanas, o aumento da população e as indústrias, salientando a qualidade da água na própria saúde e sobrevivência do ser humano.

A ser perguntada sobre a sua qualidade de vida em relação hoje e na 'Catacumba', Maria responde: "Ué de pobre, melhor a gente não vive mesmo, ganha um dinheiro gasta aqui, paga o condomínio, se escangalha uma bica, a gente tem que pagar..."

Vale lembrar que a palavra pobre constitui assim, uma percepção como tal subjetiva, da sua condição de existência como aponta Leff (2006). Embora em um mínimo de espaço em sua habitação, Marta possui eletrodomésticos (geladeira, televisão, telefone, celular), estabelecendo um padrão segundo índices em formulário do IBGE. O termo pobre foi o primeiro contato com Marta ao dizer que "a casa é de pobre", no início da entrevista. A linguagem é um dos meios na formação da representação social citada por Moscovici (1978), traduzindo a relação com o seu meio ambiente.

\section{CONCLUSÃO}

A urbanização tornou-se espelho de desenvolvimento, considerado como civilizar, polir ou embelezar (cidade ou parte dela) no aspecto da língua portuguesa e ao nível de planejamento passa a ser sinônimo das palavras: renovação, ordenamento, remoção ou reforma. O país desenvolvido deveria ser marcado pela alta industrialização, 


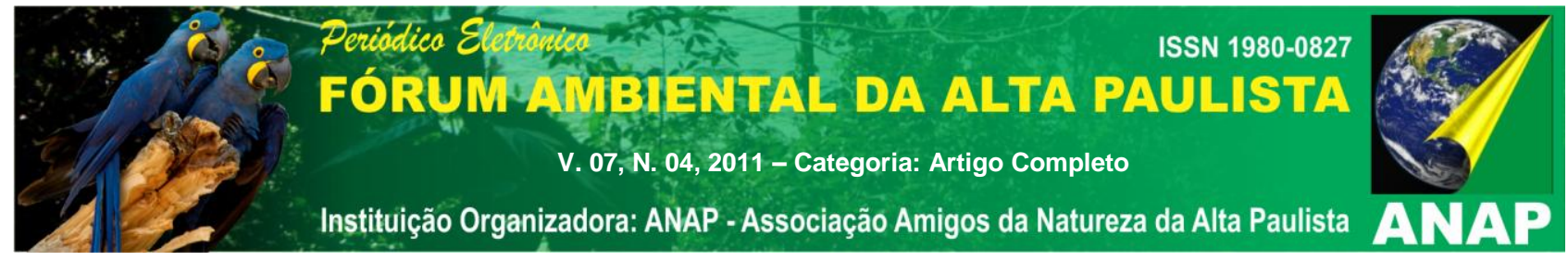

melhorias na saúde e aumento na expectativa de vida e conseqüentemente repercutindo na sua qualidade de vida e no ambiente.

As relações com o ambiente incluem as relações com o outro, assim Marta enfatiza mais as relações do ambiente entre as pessoas, descreve um lazer desconhecido, as praças e a arborização inexistentes, a precária qualidade de vida.

Nesta investigação ao descrevermos a história da cidade apontamos práticas até hoje observadas. O espaço vivido é um espaço de produção e reprodução contido em meio a lutas. Conhecer e incorporar informações de um grupo gera um processo de reprodução ou de mudanças com as suas limitações e delimitações, o território torna-se o "gueto" de um grupo.

Desde a década de 1970, o desenvolvimento ambiental prima por uma mudança no próprio comportamento ético, buscando o equilíbrio em satisfazer as necessidades básicas e "aspirações humanas", além de proporcionar uma melhor qualidade de vida. O desafio ambiental em nossa pesquisa aponta para a necessidade na modificação da representação social de um grupo em relação com o seu ambiente. Seus rios, suas praças, suas ruas, fazem parte de sua história e sobrevivência devendo ser incorporados na urbanização.

O conhecimento científico de um lado incrementou a industrialização, mas não garantiu a qualidade de vida, Oliveira (2006, p.26) salienta "entre outros fatores, a destruição e poluição do ambiente, distorções de urbanização e alienação do ser humano" constatada neste estudo na própria fala das entrevistadas e observações no local. Embora nossa pesquisa tenha foco principal na década de 1970, podemos observar as relações de agentes sociais antagônicos, também, em nossos dias.

Cabe ressaltar a importância de se reconhecer que o espaço e a cidade não são simplesmente objetos, estruturas, edificações, mas a representação de um espaço de luta e de antagonismo. Nesse sentido, Santos (1997) afirma que "a essência do espaço é social" agindo assim, o ser humano passa a atribuir um valor particular ao lugar, processo este chamado de valorização do espaço por Moraes (2005), este valor diferencia os lugares muito mais pelas características humanas e não apenas pelas naturais. Essa 


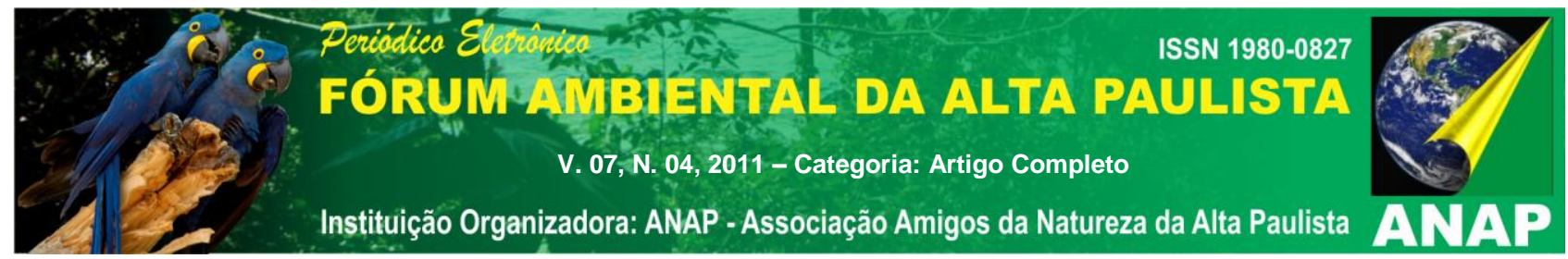

intervenção na paisagem altera o ambiente, desfigurando-o tornando-o um "elemento revelador" da sua história repercutindo a relação deste cidadão com o ambiente.

$\mathrm{Na}$ verdade, esse tema talvez seja emblemático para que fiquemos atentos às relações de poder, e assim, que permita maior participação da sociedade, no sentido de incluir na urbanização o ser humano como seu principal agente de conservação do seu ambiente na medida em que o reconhece como co-responsável.

\section{REFERÊNCIAS}

ABREU, M de A. Evolução Urbana do Rio de Janeiro. 4ª ed. Rio de Janeiro: IPP. 2008

ANDRADE, L. da S. - Qual futuro esperar para as favelas? Um debate sobre a qualidade dos espaços físicos de assentamentos populares à luz de conceitos de espaço público: In Sobre o Urbanismo. Machado, D.B.P. (orgs). PROURB, Rio de Janeiro. 2006

CARLOS, A F A - A cidade. Contexto, São Paulo. 2001

CHALHOUB, S. Cidade febril. Cortiços e epidemias na Corte imperial - Companhia das Letras, Rio de Janeiro. 1996.

CONNIFF, M L - Política a no Brasil - A ascensão do populismo 1925 -1945. Relume Dumará. Rio de Janeiro. 2006

CORREA, R. L. - Espaço urbano. Ática, Séries princípios. São Paulo, 1989

COSTA, L M S A. A paisagem em movimento: In Sobre o urbanismo.MACHADO, D B P (orgs) - Sobre o urbanismo. Viana \& Mosley. Rio de Janeiro: PROURB. 2006

FARAH, I M C. Rio de Janeiro e árvores urbanas: uma paisagem afetiva: Sobre Urbanismo, Machado, D B P (org). PROURB, Rio de Janeiro. 2006

.LEFF, E Epistemologia ambiental - Cortez, 4a ed, São Paulo.2006

LUDKE, M e ANDRÈ, M E D A - Pesquisa em Educação; Abordagens qualitativas. EPU, São Paulo. 1986 


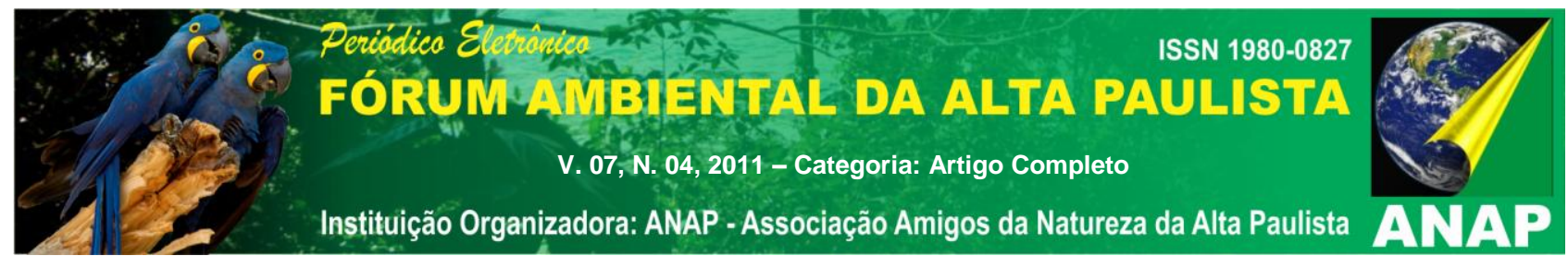

MIRANDA, A . C.; GOMES, H. P.; SILVA, M. O. Recursos Hídricos: a gestão das águas, a preservação da vida. São Paulo: All Print, 2006

MORAES, A C R - Ideologias geográficas. Espaço, cultura e política no Brasil. 5 ${ }^{\mathrm{a}} \mathrm{ed}$. Annablume, São Paulo. 2005

MOSCOVICI, S. - A representação social da Psicanálise. Zahar, Rio de Janeiro. 1978

MUMFORD, L - A cidade na historia - Vol. I e II , Itatiaia, Belo Horizonte. 1965;

A cidade na história. Suas origens, transformações e perspectivas.

Martins Fontes, São Paulo. 2004

OLIVEIRA, G B e SOUZA_LIMA, J E de (orgs). O desenvolvimento sustentável em foco. Uma contribuição multidisciplinar. Annablume. São Paulo. 2006

SANTOS, M - Espaço e método - $4^{a}$ ed. Nobel. São Paulo. 1997

O espaço do cidadão - $7^{a}$ ed. EDUSP. São Paulo. 2007

A urbanização Brasileira - 5ª ed. EDUSP São Paulo. 2008.a

A Natureza do Espaço - 4⿳亠丷a ed. EDUSP. São Paulo. 2008.b

SILVA, L H P da - História do urbanismo no Rio de Janeiro. E-papers. Rio de Janeiro, 2003

SOUZA, M J L - ABC do desenvolvimento urbano, $3^{\text {a }}$ ed. Bertrand Brasil, Rio de Janeiro. 2007

VALLADARES, L. do P. - Passa-se uma casa. Análise do programa de remoção de favelas do Rio de Janeiro - Zahar, 2 ed., SP. 1980. 